\title{
Performance Management of University Financial Budget Execution Relying on Comprehensive Budget Management Strengthening Model
}

\author{
Huwei Li $(\mathbb{D})$ and Yanlin Guo \\ Henan Institute of Economics and Trade, Zhengzhou 450000, China \\ Correspondence should be addressed to Huwei Li; lihuwei@henetc.edu.cn
}

Received 22 November 2021; Revised 15 December 2021; Accepted 27 December 2021; Published 22 January 2022

Academic Editor: Qiangyi Li

Copyright (C) 2022 Huwei Li and Yanlin Guo. This is an open access article distributed under the Creative Commons Attribution License, which permits unrestricted use, distribution, and reproduction in any medium, provided the original work is properly cited.

\begin{abstract}
In order to improve the effect of college financial budgeting, this paper combines the comprehensive budget management strengthening model to construct the school financial budget execution performance management model and selects data envelopment analysis (DEA) and stochastic frontier analysis (SFA) as empirical analysis methods. Moreover, this paper puts forward the idea of analyzing the proportion of investment funds and obtains the optimal distribution proportion through mathematical methods. Under the circumstance that the total funding input remains unchanged, this paper adjusts the investment ratio to improve the efficiency of the colleges and centers in the school and combines actual needs to construct an intelligent model of financial budget execution performance management for colleges and universities that relies on the comprehensive budget management enhancement model. In addition, the model effect verification is carried out on this basis. According to the research, the energy system proposed in this paper plays an important role in the performance management evaluation of the financial budget implementation of colleges and universities and can effectively improve the effect of college financial budgets.
\end{abstract}

\section{Introduction}

Higher education has made great progress. The number of higher education institutions has been increasing, the scale has been continuously expanded, the quality has been continuously improved, and the results have been continuously emerging, which have made great contributions to my country's economic construction and the improvement of national quality. With the reform of the economic, political, scientific, and technological systems, the reform of the higher education system has been continuously carried out, achieved certain results, and accumulated a lot of useful experience. In particular, after the 14th National Congress of the Communist Party of China proposed the establishment of a socialist market economy system, it put forward new requirements and challenges to the reform of the higher education system, also injected new vitality, and provided good opportunities [1]. In recent years, the reform of the higher education system has made new progress to varying degrees in the reform of the school-running system, management system, investment system, enrollment and graduate employment system, and school internal management system. With the continuous increase of education investment, the state or investors will pay more attention to the benefits of education investment and the education cost of schools. The school will also pay more attention to its own economic benefits, pursue the rate of return of educational capital, and strive to improve the economic benefits of education under the premise of ensuring social benefits and ensure the sustainable development of the school itself [2]. This requires the provision of a quantifiable analysis and evaluation system to scientifically evaluate the use and profitability of educational resources in colleges and universities and accurately measure capital input and output. In addition, with the increasing demand for the rational allocation of higher education resources, it is necessary to provide a quantitative and operable comprehensive analysis method for the operation and management of higher 
education institutions in order to correctly and reasonably evaluate the efficiency of the allocation of educational resources and improve the efficiency and management level of the resources of colleges and universities. All this makes it necessary to study the financial analysis system of colleges and universities [3].

The promulgation and implementation of the accounting system of public institutions have made accounting increasingly complex, and accounting data has become increasingly abundant. In recent years, a series of fiscal reforms implemented by the Ministry of Finance, including budget reforms, centralized treasury payments, and revenue and expenditure classification reforms, have also put forward new requirements for school financial work.

The current financial analysis methods can no longer meet the requirements of higher education development and various reforms. Based on this consideration, this paper establishes a performance-based financial analysis system for colleges and universities, highlights the performance analysis of colleges and universities, analyzes and compares the benefits of colleges and universities, and conducts a comprehensive and systematic analysis and evaluation of the financial work of colleges and universities in a scientific and comprehensive manner.

The college's financial budget performance evaluation system is produced under this situation. The college's financial budget performance evaluation system requires the school's intelligent financial performance management model, the use of reasonable financial evaluation indicators, and the establishment of fair and just evaluation standards and scientific. The evaluation method is to evaluate the process and results of the preparation and implementation of the financial budget of the college and give corresponding rewards or punishments. Improving the research on the performance evaluation of the financial budget of colleges and universities based on the twolevel model of colleges and universities will play a pivotal role in promoting the development of colleges and universities. A quantifiable financial performance evaluation system was evaluated for colleges and universities based on the two-level management model of colleges and universities, which can scientifically evaluate the use of resources of colleges and universities, thereby improving the efficiency of resource utilization, optimizing the structure of budget expenditures, and promoting the optimization of resources configuration, and the results of the evaluation can be used by the government and other investors to make decisions on the operation of the university, and it is also conducive to the school itself to understand the financial budget of the school and the college and to improve its own development.

This paper combines the comprehensive budget management strengthening model to construct the university financial budget execution performance management model, and on this basis, the model effect verification is carried out.

\section{Related Work}

The concept of budget was originally based on the national level to make a reasonable budget for the country's economic behavior so as to reflect the scope and trends of the country's basic policies and the government's governance direction. Literature [4] discusses the use of national income, various expenditure items, national debt, and government deficits. Literature [5] elaborated on the theory of scientific management. The authors believed that only the use of scientific and standard management methods could improve work efficiency. As a result, scientific management theory became the cornerstone of the earliest budget management theory. The US government promulgated the "Budget and Accounting Act," which became the starting point for budget control thinking. In the process of the implementation of the bill, budget management has also been widely recognized and used by various companies, and budget management has gradually become an important tool for corporate management [6]. Literature [7] introduced the concept and method of budget management based on the concept of control. The biggest contribution of this book is to develop the predecessors' unsystematic and relatively fragmented budget theory into a systematic scientific management tool. Since then, budget management theory has officially become a complete system. Literature [8] proposes the preparation method of budget management: the zero-base budget method.

With the advancement of science and technology, the theory of budget management began to enrich rapidly, and the gradual promotion of behavioral science theories and contingency theory also affected the methods of budget management. The budget management method has absorbed the theory of economic agency, as well as the advantages of strategic management and social psychology, and combined the best of a hundred families to present a prosperous scene that keeps pace with the times [9]. At the same time, budget management has also been extensively developed on a theoretical basis and methods [10].

The financial budget management model of colleges and universities in developed countries is also worth learning. For example, the management model adopted by public schools in the United States is a centralized management model. The control of funding sources and expenditures is carried out by relevant school-level departments, and the financial budget of each college must be reported to the school in advance and approved, and the budget of the college is included in the school-level budget. After the school-level budget is completed, the school submits the budget to the state government and applies for budget allocation. The school can execute the budget after the state government approves it [11]. Private universities in the United States adopt a decentralized management model. The school budgets the source of funds and expenditures and then reports the budget to the school level. The college then forms the total budget. Each college will generally report to the school at $7 \%$ to $30 \%$ and pay part of the funds as the basis for school-level department expenditures [12]. Another example is the United Kingdom. The funding for university education in the UK comes from government funding. Funds are allocated to schools through the Higher Education Appropriation Committee. Each university establishes a university finance committee. 
The university finance committee will conduct on-campus management based on the actual conditions of each college and other departments. Allocation of funds: the school's fund income and expenditure are settled in the computing center of each campus through a unified account [13]. If there is a shortage of funds in a department that year, the school can take the method of borrowing after the investigation, but the amount in the second year must be deducted from the funds of the second year if there is overspending in the second year. That is, there is a problem with the responsibilities of the dean of expenditures, and the dean of the school needs to be replaced [14]. Another example is Australia and New Zealand. Colleges and universities in these two countries have carried out strict budget management. Each budget process is very strict. After the school has issued a budget draft, it needs to be announced to the entire school to listen to the teachers and students. After the opinions, the college committee will verify and approve them before they can be implemented. Moreover, the approved budget draft does not allow anyone to modify it. If it is necessary to modify it, it must be approved in accordance with specific statutory procedures. Moreover, when supervising the budget, the budget is not only supervised by the budget executive committee, finance committee, and teachers and students but also supervised by various public interest entities, such as accounting firms and other related auditing departments [15]. The budgets of Australia and New Zealand are based on the budget between the centralized budget and the decentralized budget. They are the first school's colleges and related departments to first carry out the department's budget and then submit the budget report, and the school will then conduct a summary analysis of the budget report. On this basis, they prepare the total budget. The budgeting method of "means within your means" makes budget deficits rarely occur [16].

\section{Comprehensive Budget Management and Financial Budget Performance Model}

3.1. Budget Performance Evaluation Method. The performance evaluation methods of enterprises and institutions mainly adopt traditional performance evaluation methods and evaluation methods based on efficiency measurement. The traditional performance evaluation methods commonly used in academia include the key performance indicator (KPls) evaluation method and the balanced scorecard evaluation method. And the evaluation methods based on efficiency measurement include data envelopment analysis (DEA) and stochastic frontier analysis (SFA).

\subsubsection{Traditional Performance Evaluation Methods.} Because the balanced scorecard (BSC) evaluation method is closely related to the strategic goals of enterprises, the current phenomenon of unclear and difficult implementation of the strategic goals of Chinese enterprises is widespread. Therefore, more companies choose key performance indicator evaluation methods (KPIs) for budget performance evaluation.
Although the key performance indicator evaluation method has overcome the shortcomings of some performance evaluation methods that only evaluate input indicators or output indicators, there are still some problems in the key performance indicator evaluation method. We assume that there are two colleges, college A and college B. College A's financial investment in student training is 50, and the financial investment in scientific research is 100 . College B's financial investment in student training is 100 , and the financial investment in scientific research is 50 . In terms of output, college A has an employment rate score of 40 and a research score of 40 . College B has an employment rate score of 70 and a research score of 15 . This results in a Fox paradox as shown in Table 1 [17].

It can be seen from Table 1 that although college A performs better than college B on both KPIs, in general, college B performs better than college A. This situation actually stems from the ignorance of resource allocation by key performance indicators. Although college A is better than college B in every KPI, college B is better than college A in terms of overall performance because college $\mathrm{B}$ allocates more resources to the scientific research business with relatively high output efficiency.

Data envelopment analysis (DEA) aims to use linear programming to calculate production units, especially the technical efficiency of production units that contain multiple inputs and multiple outputs.

DEA analysis includes the CCR model based on the fixed return to scale assumption and the BCC model based on the variable return to scale assumption. At the same time, each model is divided into an input angle model (keep output unchanged, minimize input) and an output angle model (keep input unchanged, and maximize output) according to the perspective of evaluation. Therefore, this paper uses the CCR model from the input perspective, the CCR model from the output perspective, the BCC model from the input perspective, and the BCC model from the output perspective to calculate the technical efficiency of the evaluated decision-making unit. The linear programming formulas corresponding to the four models are shown in the following.

The CCR model of the investment perspective is [18]

$$
\begin{aligned}
\min _{E, \lambda} E & \\
E x_{0}-X \lambda & \geq 0, \\
y_{0}-Y \lambda & \leq 0, \\
\lambda & \geq 0 .
\end{aligned}
$$

The CCR model from the output perspective is

$$
\begin{aligned}
\max _{F, \lambda} F, & \\
x_{0}-X \lambda & \geq 0, \\
F y_{0}-Y \lambda & \leq 0, \\
\lambda & \geq 0 .
\end{aligned}
$$

The BCC model of the investment perspective is 
TABLE 1: Fox theory.

\begin{tabular}{lccc}
\hline College & Employment rate score/financial investment & Research score/financial investment & Total score/financial investment \\
\hline A & 0.80 & 0.40 & $8 / 15$ \\
B & 0.70 & 0.30 & $17 / 30$ \\
\hline
\end{tabular}

$$
\begin{aligned}
\min _{E, \lambda} E, & \\
E x_{0}-X \lambda & \geq 0, \\
y_{0}-Y \lambda & \leq 0, \\
e \lambda & =1, \\
\lambda & \geq 0 .
\end{aligned}
$$

The BCC model from the output perspective is

$$
\begin{aligned}
\max _{F, \lambda} F & \\
x_{0}-X \lambda & \geq 0, \\
F y_{0}-Y \lambda & \leq 0, \\
e \lambda & =1, \\
\lambda & \geq 0 .
\end{aligned}
$$

In the above formula, $x_{0}$ represents the vector composed of multiple input data of the evaluated decision-making unit, $y_{0}$ represents the vector composed of multiple output data of the evaluated decision-making unit, $X$ represents the matrix composed of all the input data vectors of the decisionmaking unit, $Y$ represents all A matrix composed of output data vectors of decision-making units, $e=(1,1, \ldots, 1)$, and $\lambda$ represents the linear combination coefficient of the linear combination of input-output vectors of each decisionmaking unit. For the results of the above planning, the result of the input angle model $\left(E^{*}\right)$ and the reciprocal $\left(1 / F^{*}\right)$ of the output angle model result is the technical efficiency of the evaluated decision-making unit.

The stochastic frontier analysis (SFA) first uses the total output data to regress the input data of each decisionmaking unit. The regression formula is as follows [19]:

$$
\begin{aligned}
\ln Y_{k}= & \alpha_{0}+\alpha_{1} \ln x_{1 k}+\alpha_{2} \ln x_{2 k} \\
& +\cdots+\alpha_{3} \ln x_{3 k}+v_{k}-u_{k} .
\end{aligned}
$$

Among them, $Y_{k}$ represents the total output of the $k$-th decision-making unit, $x_{i k}$ represents the $i$-th input of the $k$ th decision-making unit, $v_{k}$ is a normal distribution random item with a mean value of 0 , and $u_{k}$ is a random term of a half-normal distribution with mean 0 . Then, we use the regression results to further calculate the technical efficiency of each decision-making unit [20]:

$$
\frac{e^{\ln \widehat{Y}_{k}-\widehat{u}_{k}}}{e^{\ln \widehat{Y}_{k}}}=e^{-\widehat{u}_{k}}
$$

Among them, $\ln \widehat{Y}_{k}$ is the estimated value of the total output of the $k$-th decision-making unit according to the regression result of formula (5), and $\hat{u}_{k}$ is the estimated value of the seminormal distribution random item.
Data envelopment analysis (DEA) can only get the relative efficiency of each college. The stochastic frontier analysis method (SFA) obtains the absolute efficiency of each college, and its results can directly reflect whether the performance evaluation of each college is efficient or inefficient. The comparison table between the DEA method and the SFA method is shown in Table 2 [21].

3.2. Data Envelopment Analysis (DEA). Data envelopment analysis (DEA) is an operations research method that uses linear programming to measure the production boundaries of multiple decision-making departments and the Farrell efficiency of a single decision-making department. It satisfies the following three assumptions. The first is the adjustability assumption; that is, the decision-making unit can adjust its input and output. The second is the convexity hypothesis; that is, the weighted average of the input and output of any two decision-making units in the technology set still belongs to the technology set. The third is the assumption of fixed returns to scale; that is, the input and output of a decision-making unit can be scaled up or down in equal proportions. The DEA method has a variety of derivative models. In empirical research, the CCR model and BCC model are commonly used to measure technical efficiency.

3.2.1. Constant Return to Scale Model (CCR Model). The CCR model is also called the constant return to scale model. The model assumes that the effective frontier of input and output satisfies the constant return to scale; that is, the technology set $T$ satisfies both the adjustability assumption and the fixed return to scale assumption. According to the difference of Farrell index selection, it can be divided into input-oriented CCR model and output-oriented CCR model.

In the input-oriented CCR model, the efficiency of the evaluated decision-making unit DMU can be obtained by solving the following linear program:

$$
\begin{aligned}
& \min _{E, \lambda} E \\
& E\left(\mathrm{IT}_{0}, \mathrm{IR}_{0}, \mathrm{IE}_{0}\right)^{T}-\sum_{i=1}^{21} \lambda_{i}\left(\mathrm{IT}_{i}, \mathrm{IR}_{i}, \mathrm{IE}_{i}\right)^{T} \geq 0, \\
& \left(\mathrm{OT}_{0}, \mathrm{OR}_{0}\right)^{T}-\sum_{i=1}^{21} \lambda_{i}\left(\mathrm{OT}_{i}, \mathrm{OR}_{i}\right)^{T} \leq 0, \\
& \left(\lambda_{1}, \lambda_{2}, \ldots, \lambda_{21}\right) \geq 0 .
\end{aligned}
$$

Among them, $E$ represents the Farrell index of input, $\left(\mathrm{IT}_{0}, \mathrm{IR}_{0}, \mathrm{IE}_{0}\right)$ represents the input data of DMU0, $\left(\mathrm{OT}_{i}\right.$, $\left.O R_{i}\right)$ represents the output data of DMU0, $\left(\mathrm{IT}_{i}, \mathrm{IR}_{i}, \mathrm{IE}_{i}\right)$ represents the input data of the $i$-th college, $\left(\mathrm{IT}_{i}, \mathrm{IR}_{i}, \mathrm{IE}_{i}\right)$ represents the output data of the $i$-th college, and $\left(\lambda_{1}, \lambda_{2}, \ldots, \lambda_{21}\right)$ represents the linear combination 
TABle 2: Comparison table of DEA method and SFA method.

\begin{tabular}{lcc}
\hline & DEA method & SFA method \\
\hline Method basis & $\begin{array}{c}\text { Linear programming model } \\
\text { Nonparametric method }\end{array}$ & $\begin{array}{c}\text { Econometric model } \\
\text { Parametric method }\end{array}$ \\
\hline $\begin{array}{l}\text { Features } \\
\text { It is impossible to examine the process of the influence of input } \\
\text { on output and cannot reflect the importance of each input } \\
\text { Relative efficiency among decision-making units } \\
\text { Strict evaluation }\end{array}$ & $\begin{array}{c}\text { Can examine the impact of input on output } \\
\text { and can reflect the importance of each input } \\
\text { Absolute efficiency of the decision-making unit } \\
\text { extreme values }\end{array}$ & Mederate evaluation \\
\hline $\begin{array}{l}\text { Rerestimation of } \\
\text { Refficiency among decision-making units }\end{array}$ & Absolute efficiency of the decision-making unit \\
\hline
\end{tabular}

coefficient of input data and output data of 21 colleges. The solution of the above formula is $E$, which is the input-oriented technical efficiency (CCR efficiency) of the evaluated decision-making unit DMU0.

In the output-oriented CCR model, the efficiency of the decision-making unit DMU can be obtained by solving the following linear programming:

$$
\begin{aligned}
& \max _{F, \lambda} E, \\
& E\left(\mathrm{IT}_{0}, \mathrm{IR}_{0}, \mathrm{IE}_{0}\right)^{T}-\sum_{i=1}^{21} \lambda_{i}\left(\mathrm{IT}_{i}, \mathrm{IR}_{i}, \mathrm{IE}_{i}\right)^{T} \geq 0, \\
& F\left(\mathrm{OT}_{0}, \mathrm{OR}_{0}\right)^{T}-\sum_{i=1}^{21} \lambda_{i}\left(\mathrm{OT}_{i}, \mathrm{OR}_{i}\right)^{T} \leq 0, \\
& \left(\lambda_{1}, \lambda_{2}, \ldots, \lambda_{21}\right) \geq 0 .
\end{aligned}
$$

Among them, $F$ represents the Farrell index of output, the solution of the above formula is $F_{C}^{*}$, and then $1 / F_{C}^{*}$ represents the output-oriented technical efficiency (CCR efficiency) of the evaluated decision-making unit $\mathrm{DMU}_{0}$.

3.2.2. Variable Return to Scale Model (BCC Model). The BCC model is also known as the variable return to scale model. The model assumes that the effective frontier of input and output satisfies variable returns to scale, and its technology set $T$ satisfies both the adjustability and convexity assumptions. Like the CCR model, the BCC model is also divided into an outputoriented BCC model and an input-oriented BCC model.

In the input-oriented BCC model, the efficiency of the evaluated decision-making unit $\mathrm{DMU}_{0}$ can be obtained by solving the following linear program:

$$
\begin{array}{r}
\min _{E, \lambda} E, \\
E\left(\mathrm{IT}_{0}, \mathrm{IR}_{0}, \mathrm{IE}_{0}\right)^{T}-\sum_{i=1}^{21} \lambda_{i}\left(\mathrm{IT}_{i}, \mathrm{IR}_{i}, \mathrm{IE}_{i}\right)^{T} \geq 0, \\
\left(\mathrm{OT}_{0}, \mathrm{OR}_{0}\right)^{T}-\sum_{i=1}^{21} \lambda_{i}\left(\mathrm{OT}_{i}, \mathrm{OR}_{i}\right)^{T} \leq 0, \\
\sum_{i=1}^{21} \lambda_{i}=1, \\
\left(\lambda_{1}, \lambda_{2}, \ldots, \lambda_{21}\right) \geq 0 .
\end{array}
$$

Among them, $E$ represents the Farrell index of input, and the solution of the above formula is $E_{B}^{*}$, which represents the input-oriented pure technical efficiency (BCC efficiency) of the evaluated decision-making unit $\mathrm{DMU}_{0}$.
In the output-oriented BCC model, the efficiency of the evaluated decision-making unit DMU can be obtained by solving the following linear program:

$$
\begin{aligned}
& \max _{F, \lambda} E, \\
&\left(\mathrm{IT}_{0}, \mathrm{IR}_{0}, \mathrm{IE}_{0}\right)^{T}-\sum_{i=1}^{21} \lambda_{i}\left(\mathrm{IT}_{i}, \mathrm{IR}_{i}, \mathrm{IE}_{i}\right)^{T} \geq 0, \\
& F\left(\mathrm{OT}_{0}, \mathrm{OR}_{0}\right)^{T}-\sum_{i=1}^{21} \lambda_{i}\left(\mathrm{OT}_{i}, \mathrm{OR}_{i}\right)^{T} \leq 0, \\
& \sum_{i=1}^{21} \lambda_{i}=1, \\
&\left(\lambda_{1}, \lambda_{2}, \ldots, \lambda_{21}\right) \geq 0 .
\end{aligned}
$$

The solution of the above formula is $F_{B}^{*}$, and $1 / F_{B}^{*}$ represents the output-oriented pure technical efficiency (BCC efficiency) of the evaluated decision-making unit $\mathrm{DMU}_{0}$.

3.3. Stochastic Frontier Analysis (SEA). Stochastic frontier analysis (SFA) is also one of the mainstream methods to calculate Farrell's efficiency in the performance evaluation process. Different from the DEA method, the SFA method uses an econometric model and a nonlinear programming model to generate a technology set and then uses the boundary of the technology set to estimate the efficiency of the internal decision-making unit of the technology set.

Based on the Cobb-Douglas production function hypothesis and the seminormal distribution hypothesis, the SFA model with multiple inputs and single outputs can be obtained as follows:

$$
\begin{aligned}
\text { ln Output } & =\alpha_{0}+\alpha_{1} \ln \mathrm{IT}_{k} \\
& +\alpha_{2} \ln \mathrm{IR}_{k}+\alpha_{3} \ln \mathrm{IE}_{k}+v_{k}-u_{k} .
\end{aligned}
$$

Among them, $v_{k} \sim N\left(0, \sigma_{v}^{2}\right)$ and $u_{k} \sim N_{+}\left(0, \sigma_{u}^{2}\right)$. In this model, the random term $v_{k}$ retains the OLS model's measure of output randomness, while $u_{k}$ represents the inefficiency of each decision-making unit relative to the production possibility boundary. In the regression results, the larger $\widehat{u_{k}}$, the lower the efficiency of the decision-making unit $k$. The smaller $\widehat{u_{k}}$, the higher the efficiency of the decision-making unit $k$.

In terms of efficiency evaluation, referring to the Farrell efficiency of the output, the input data of the control decision unit $k$ remains unchanged, and the Farrell efficiency of the output can be obtained as follows: 


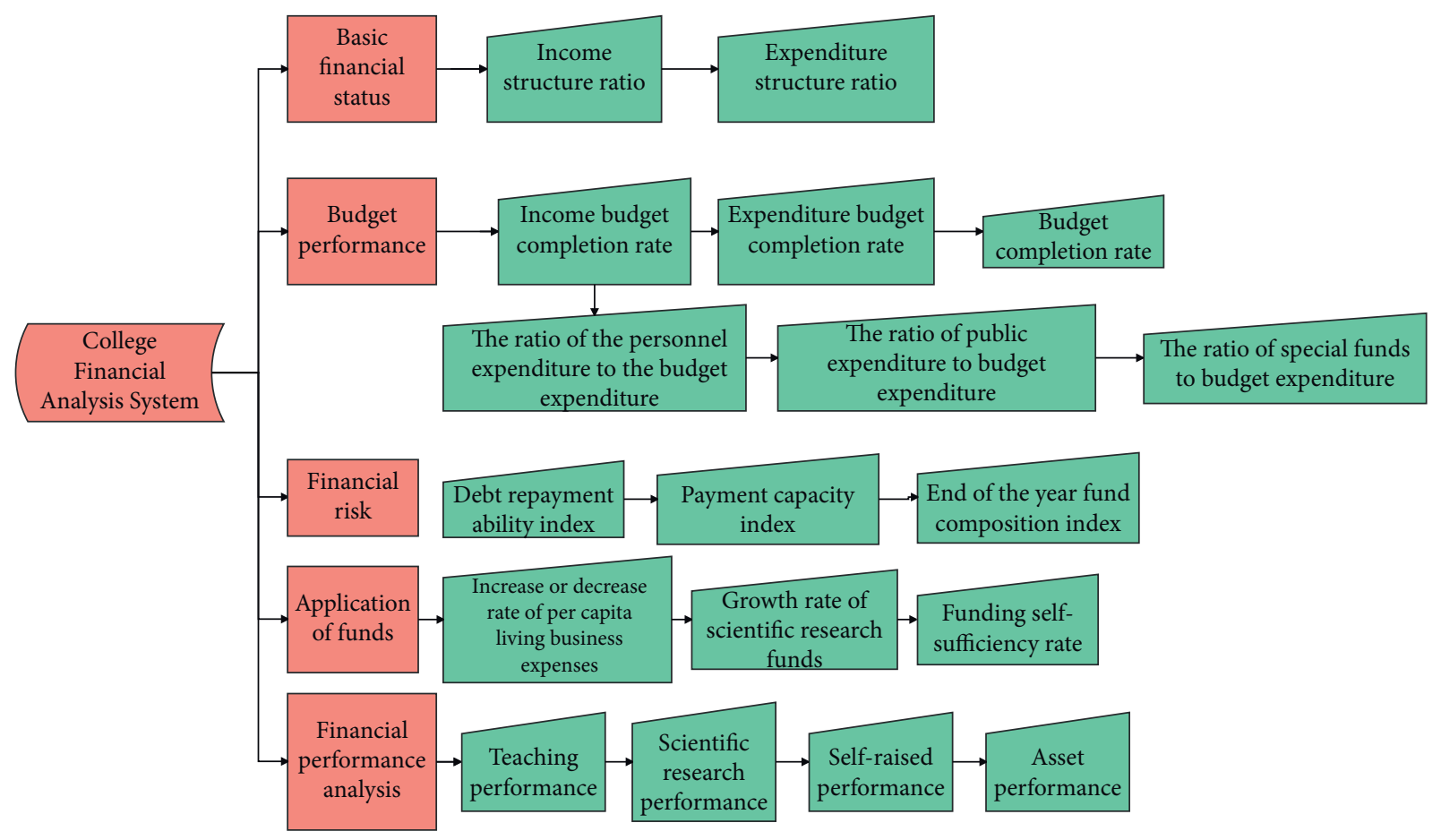

FIGURE 1: University financial analysis system.

$$
F=\frac{e^{\operatorname{lnOuput}}}{e^{\operatorname{lnOuput}-\hat{u_{k}}}}=e^{\hat{u_{k}}} .
$$

The algorithm takes the reciprocal of the output Farrell efficiency, and then the efficiency evaluation $e^{-\widehat{u_{k}}}$ for each decision-making unit can be obtained.

\section{Performance Management of University Financial Budget Execution Relying on Comprehensive Budget Management Strengthening Model}

After financial analysis methods and indicator design, a university financial analysis system with performance analysis as the core is finally established, as shown in Figures 1 and 2 .

(1) The basic premise of the implementation of performance evaluation is to determine the performance target. Therefore, before preparing the budget, it is necessary to clarify the final performance goals of each budgeting department (faculty). This performance goal must be consistent with the overall development goals of the school, and the realization of the departmental performance goals must be conducive to the realization of the overall performance goals of the university. This is the basis for each department to prepare budgets, and it is also an action indicator for each budget execution department to execute the budget. (2) When each budget implementation unit prepares a budget, it needs to determine an action plan based on performance goals, that is, what channels and methods can be used to maximize its goals, and then needs to determine various revenue and expenditure budgets based on the action plan.
(3) In the execution of the budget, due to the performance goals, each budget execution department must constantly compare the performance goals during the execution process, and through the execution analysis, find the problems and reasons to ensure that the budget expenditures do not deviate from the original basic direction. (4) It is necessary to combine the performance goals of each budget execution department, evaluate the final performance results of each department through the performance evaluation of the budget execution results, and use the results to reward, penalize, and encourage the relevant departments. (5) Finally, it is necessary to analyze and summarize the above performance evaluation results, use this to guide and adjust the next performance target and performance budget formulation, and restrain the blindness and arbitrariness of various departments in the budget preparation and implementation process (Figure 3 ).

Comprehensive evaluation mainly focuses on inspecting and measuring the actual results of government departments' activities and using certain evaluation models to compare and analyze them with performance evaluation indicators. From this, a comprehensive evaluation and a comprehensive summary of the overall situation of inputs, outputs, and results are carried out. The relationship between its core factors is shown in Figure 4.

Figure 5 is the overall structure diagram of the data warehouse, which reflects the main components of the data warehouse. The data warehouse obtains data from multiple source data, stores it in the internal database of the data warehouse after cleaning and classification, and provides data information to the data warehouse through the data loading tool of the data warehouse. 


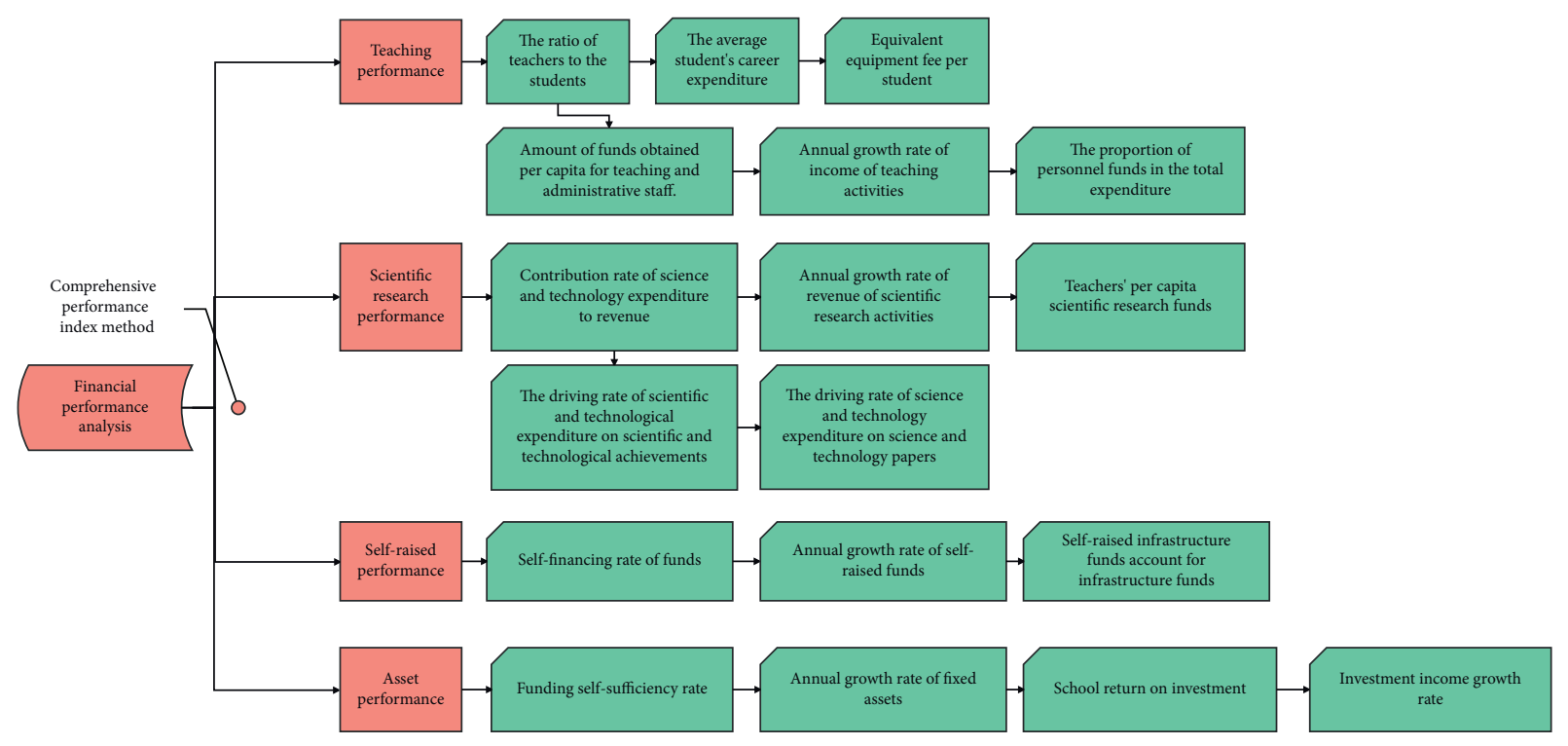

FIGURE 2: Financial performance analysis system.

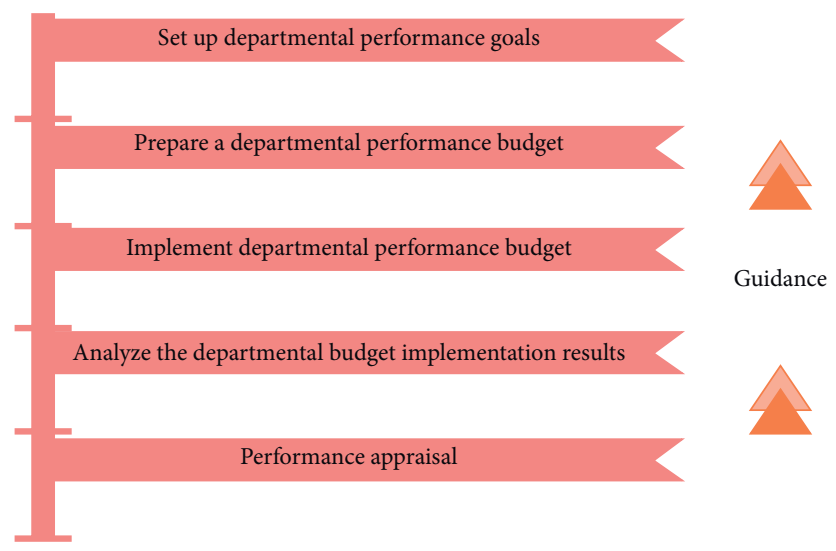

FIGURE 3: The performance budget management system of colleges and universities.

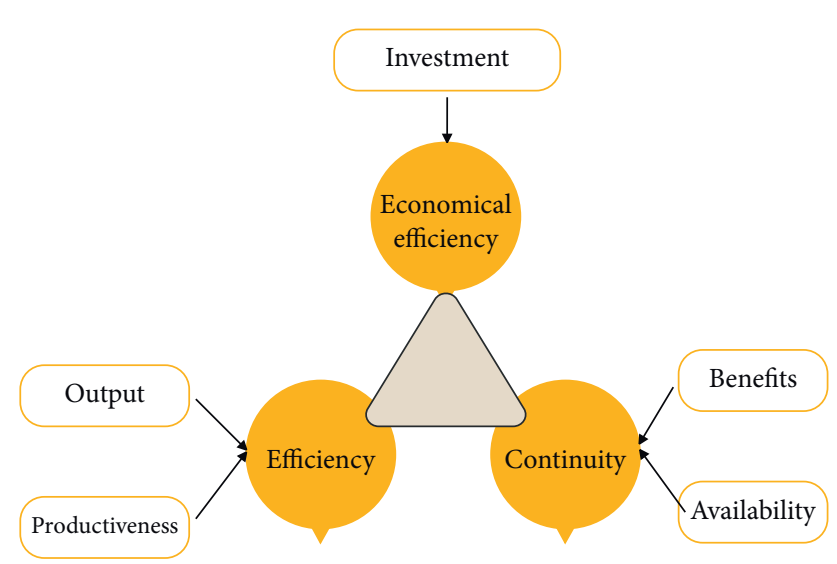

FIgURE 4: The relationship between the core factors of comprehensive evaluation.

As shown in Figure 6, the budgetary income of colleges and universities mainly comes from financial appropriations and social resources of the school's self-financing part. At this time, this is the first decision of resource allocation in colleges and universities. The realization of the first optimization of resource allocation depends on the secondary optimization of the input resources of colleges and universities, and it belongs to the microdecision-making of the optimal allocation of resources.

Calculation performance evaluation is the cause of budget performance feedback, and budget performance feedback is the cause of the next round of budget performance indicator system. As a result, the cycle continues until the goal of improving employee and organizational performance is achieved. The causal chain of the budget performance management system can be shown in Figure 7.

Department budget is the basis of university budget performance management. The implementation of target management and performance evaluation are inseparable from the department budget, as shown in Figure 8 .

In this paper, the performance of the above model is verified. Starting from the actual situation, the budget effect of the model in this paper is evaluated through multiple sets of university financial budget data, and the results shown in Table 3 are obtained. 


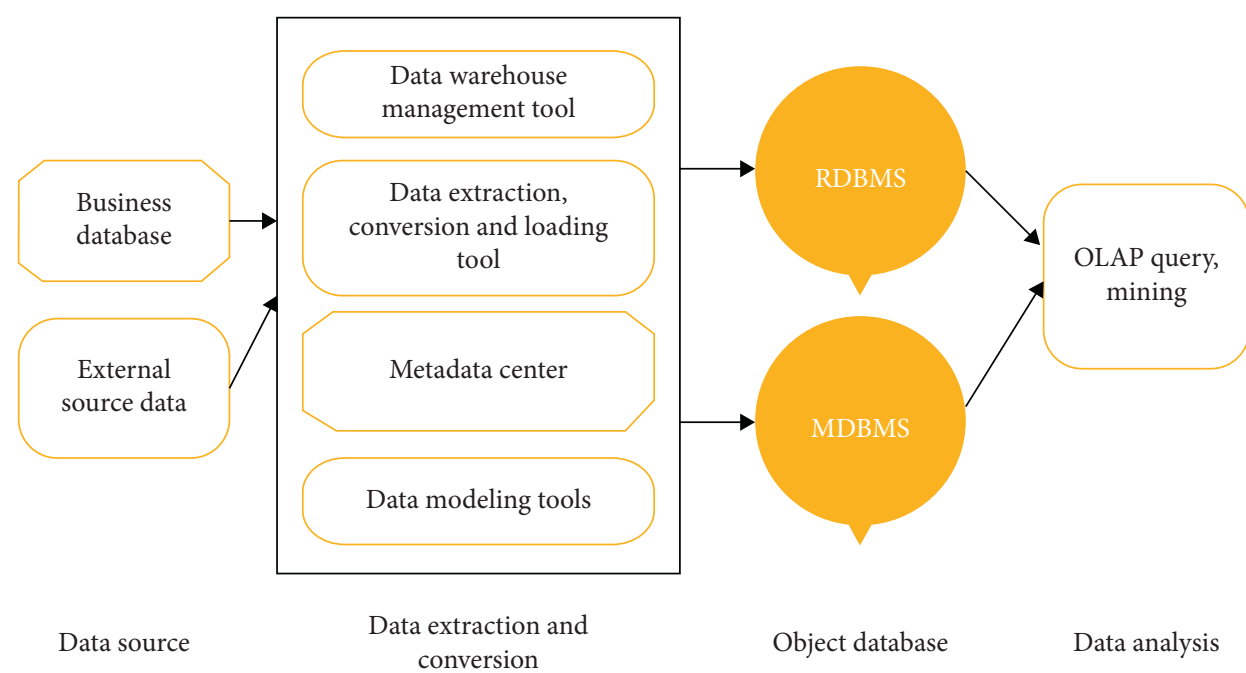

Figure 5: The overall structure of the data warehouse.

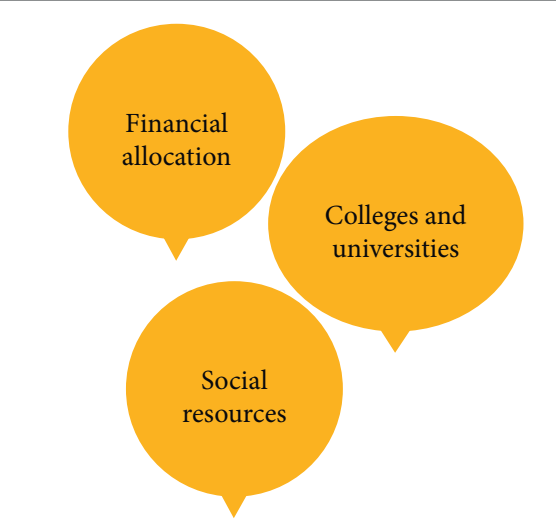

Initial resource configuration

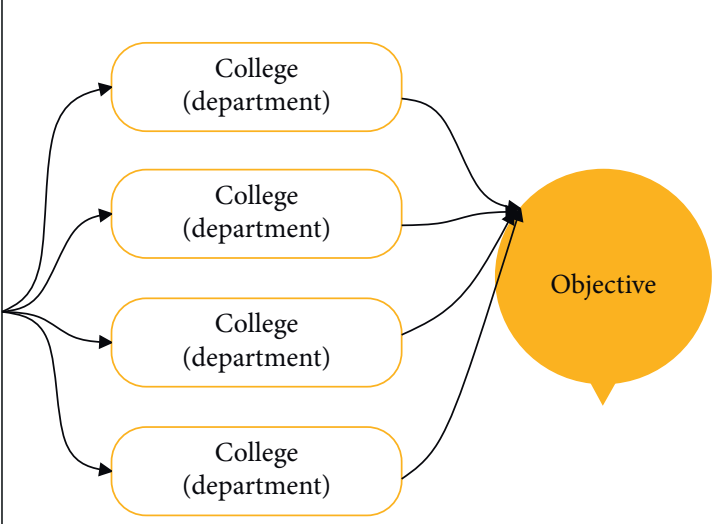

Secondary resource allocation

FIGURE 6: Budget resource allocation of colleges and universities.

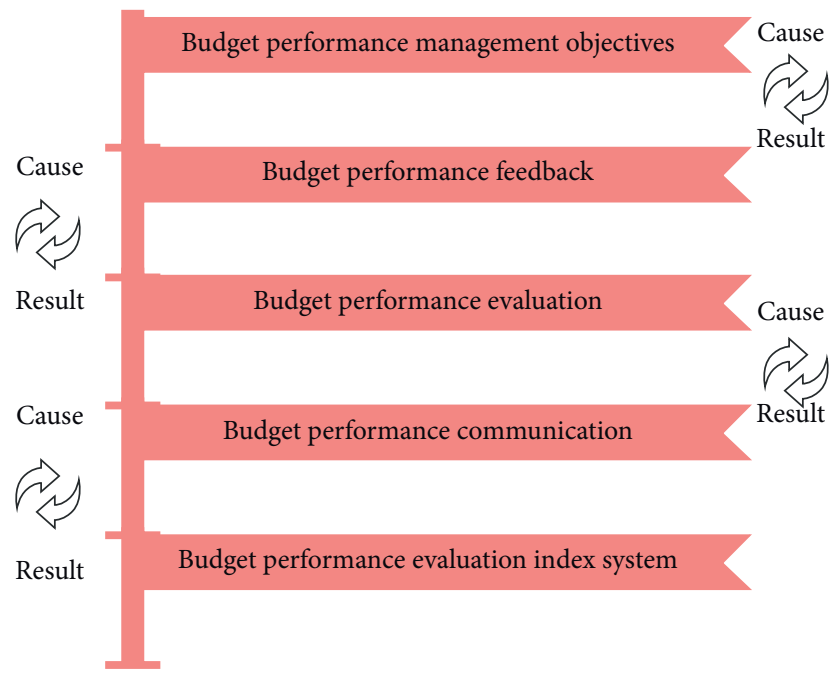

FIGURE 7: Schematic diagram of the causal chain of the budget performance management system. 


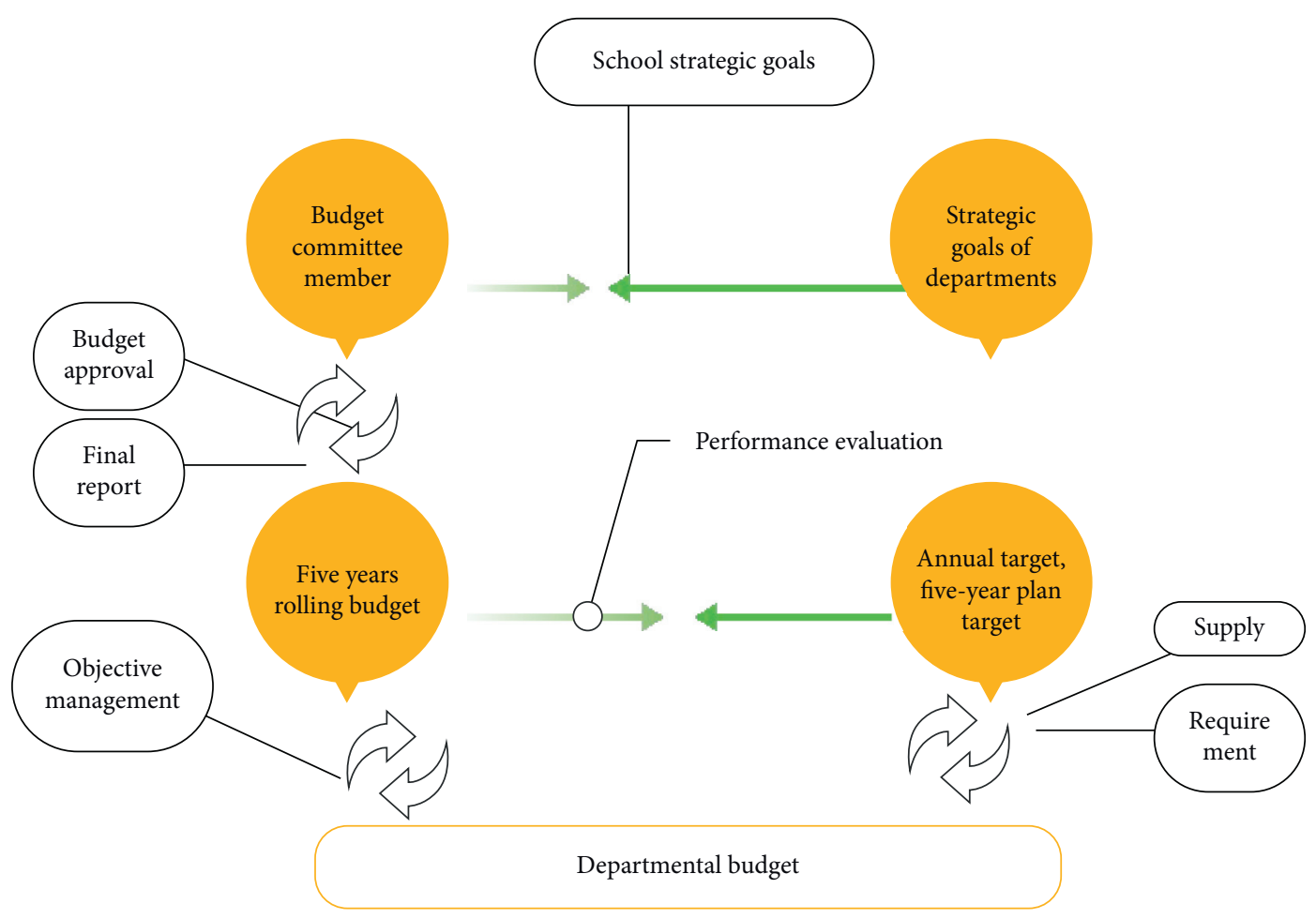

FIGURE 8: Schematic diagram of departmental budget.

TABle 3: Evaluation of the effect of the financial budget of the intelligent system colleges and universities.

\begin{tabular}{|c|c|c|c|c|}
\hline Budget evaluation & No. & Budget evaluation & No. & Budget evaluation \\
\hline 92.01 & 18 & 88.56 & 35 & 86.08 \\
\hline 85.41 & 19 & 94.19 & 36 & 91.12 \\
\hline 95.55 & 20 & 90.44 & 37 & 92.66 \\
\hline 90.30 & 21 & 93.69 & 38 & 94.77 \\
\hline 86.72 & 22 & 96.85 & 39 & 86.21 \\
\hline 94.45 & 23 & 94.04 & 40 & 95.89 \\
\hline 96.52 & 24 & 94.18 & 41 & 96.05 \\
\hline 86.14 & 25 & 87.91 & 42 & 93.96 \\
\hline 93.47 & 26 & 86.89 & 43 & 96.51 \\
\hline 86.72 & 27 & 88.29 & 44 & 91.43 \\
\hline 96.03 & 28 & 85.67 & 45 & 94.58 \\
\hline 92.84 & 29 & 87.39 & 46 & 86.22 \\
\hline 89.56 & 30 & 94.56 & 47 & 87.06 \\
\hline 87.05 & 31 & 91.47 & 48 & 93.16 \\
\hline 90.79 & 32 & 91.51 & 49 & 90.68 \\
\hline 94.16 & 33 & 91.68 & 50 & 94.89 \\
\hline 96.36 & 34 & 88.02 & 51 & 87.88 \\
\hline
\end{tabular}

TABLE 4: Performance management evaluation of financial budget implementation in colleges and universities.

\begin{tabular}{lccccc}
\hline No. & Performance evaluation & No. & Performance evaluation & No. & Performance evaluation \\
\hline 1 & 74.86 & 18 & 80.44 & 35 & 87.88 \\
2 & 91.27 & 19 & 85.26 & 36 & 81.35 \\
3 & 91.88 & 20 & 89.45 & 37 & 91.67 \\
4 & 84.39 & 21 & 87.11 & 38 & 76.26 \\
5 & 82.14 & 22 & 86.66 & 39 & 85.64 \\
6 & 87.75 & 23 & 87.98 & 40 & 88.11 \\
7 & 87.91 & 24 & 77.51 & 41 & 89.16 \\
\hline
\end{tabular}


TABLE 4: Continued.

\begin{tabular}{|c|c|c|c|c|c|}
\hline No. & Performance evaluation & No. & Performance evaluation & No. & Performance evaluation \\
\hline 8 & 88.33 & 25 & 84.50 & 42 & 77.23 \\
\hline 9 & 74.34 & 26 & 83.60 & 43 & 86.07 \\
\hline 10 & 74.91 & 27 & 82.80 & 44 & 88.58 \\
\hline 11 & 89.21 & 28 & 84.87 & 45 & 83.68 \\
\hline 12 & 90.29 & 29 & 81.28 & 46 & 74.55 \\
\hline 13 & 75.60 & 30 & 89.95 & 47 & 87.73 \\
\hline 14 & 91.48 & 31 & 77.66 & 48 & 81.33 \\
\hline 15 & 83.44 & 32 & 82.40 & 49 & 77.22 \\
\hline 16 & 83.08 & 33 & 84.62 & 50 & 84.63 \\
\hline 17 & 87.95 & 34 & 76.67 & 51 & 83.78 \\
\hline
\end{tabular}

From the above research, we can see that the intelligent system proposed in this paper can play an important role in the financial budget of colleges and universities. On this basis, the performance management evaluation of the financial budget of colleges and universities is carried out, and the results shown in Table 4 are obtained.

From the above research, it can be seen that the system proposed in this paper plays an important role in the performance management evaluation of financial budget implementation in universities and can effectively improve the effect of financial budgets in universities.

\section{Conclusion}

Financial analysis of colleges and universities is the use of business plans, accounting statements, and other relevant materials to systematically analyze, compare, and evaluate the financial status of colleges and universities in a certain period of time and obtain the regular understanding of the economic activities and career development of colleges and universities. College financial analysis is an important part of college financial management. Its guiding ideology is to focus on efficiency, comprehensively strengthen financial management, improve the level of financial management, maximize revenue and reduce expenditure, and allow limited funds to maximize social and economic benefits to promote the development of higher education. With the reform and development of my country's higher education system and the continuous enhancement of the vitality of higher education institutions, the financial analysis of schools is also facing a more complicated situation. This paper combines the comprehensive budget management strengthening model to construct the university financial budget execution performance management model and verify the model effect. The research results show that the system proposed in this paper plays an important role in the performance management evaluation of the financial budget implementation of colleges and universities and can effectively improve the effect of college financial budgets.

\section{Data Availability}

The labeled datasets used to support the findings of this study are available from the corresponding author upon request.

\section{Conflicts of Interest}

The authors declare no conflicts of interest.

\section{Acknowledgments}

This study was sponsored by the Henan Institute of Economics and Trade.

\section{References}

[1] A. Omitogun and K. Al-Adeem, "Auditors' perceptions of and competencies in big data and data analytics: an empirical investigation," International Journal of Computer Auditing, vol. 1, no. 1, pp. 92-113, 2019.

[2] K. S. Kumar, "Factors affecting the adoption of computerized accounting system (CAS) among smes in Jaffna District," SAARJ Journal on Banking \& Insurance Research, vol. 8, no. 6, pp. 11-15, 2019.

[3] B. L. Handoko, A. N. Mulyawan, J. Tanuwijaya, and F. Tanciady, "Big data in auditing for the future of data driven fraud detection," International Journal of Innovative Technology and Exploring Engineering, vol. 9, no. 3, pp. 2902-2907, 2020.

[4] Z. Rezaee, A. Dorestani, and S. Aliabadi, "Application of time series analyses in big data: practical, research, and education implications," Journal of Emerging Technologies in Accounting, vol. 15, no. 1, pp. 183-197, 2018.

[5] E. Huerta and S. Jensen, "An accounting information systems perspective on data analytics and Big Data," Journal of Information Systems, vol. 31, no. 3, pp. 101-114, 2017.

[6] S. Balne, "Analysis on research methods in bigdata applications," International Journal of Innovative Research in Computer and Communication Engineering, vol. 8, no. 10, pp. 4059-4063, 2020.

[7] P. B. De Laat, "Algorithmic decision-making based on machine learning from Big Data: can transparency restore accountability?" Philosophy \& Technology, vol. 31, no. 4, pp. 525-541, 2018.

[8] G. Tucker, "Sustainable product lifecycle management, industrial big data, and internet of things sensing networks in cyber-physical system-based smart factories," Journal of SelfGovernance and Management Economics, vol. 9, no. 1, pp. 9-19, 2021.

[9] P. B. de Laat, "Big data and algorithmic decision-making: can transparency restore accountability?" ACM SIGCAS-Computers and Society, vol. 47, no. 3, pp. 39-53, 2017.

[10] T. E. Marshall and S. L. Lambert, "Cloud-based intelligent accounting applications: accounting task automation using 
IBM watson cognitive computing," Journal of Emerging Technologies in Accounting, vol. 15, no. 1, pp. 199-215, 2018.

[11] D. Chessell and O. Neguriţă, "Smart industrial value creation, cyber-physical production networks, and real-time big data analytics in sustainable Internet of Things-based manufacturing systems," Journal of Self-Governance and Management Economics, vol. 8, no. 4, pp. 49-58, 2020.

[12] B. Abdualgalil and S. Abraham, "Efficient machine learning algorithms for knowledge discovery in big data: a literature review," Database, vol. 29, no. 5, pp. 3880-3889, 2020.

[13] O. Throne and G. Lăzăroiu, "Internet of Things-enabled sustainability, industrial big data analytics, and deep learningassisted smart process planning in cyber-physical manufacturing systems," Economics, Management, and Financial Markets, vol. 15, no. 4, pp. 49-58, 2020.

[14] E. Nica, C. I. Stan, A. G. Luţan, and R. S. Oa, "Internet of things-based real-time production logistics, sustainable industrial value creation, and artificial intelligence-driven big data analytics in cyber-physical smart manufacturing systems," Economics, Management, and Financial Markets, vol. 16, no. 1, pp. 52-63, 2021.

[15] B. L. S. Almutairi, "Impact of covid19 on accounting profession from the perspective of a sample of head of accounting departments within kuwaiti manufacturing sector," Psychology and Education Journal, vol. 58, no. 2, pp. 4758-4768, 2021.

[16] V. Q. Thong, "Factors defining the effectiveness of integrated accounting information system in ERP environment-Evidence from Vietnam's enterprises," Economics And Business Administration, vol. 7, no. 2, pp. 96-110, 2017.

[17] J. R. A. Q. Al Natour, "The impact of information technology on the quality of accounting information (SFAC NO 8, 2010)," Turkish Journal of Computer and Mathematics Education (TURCOMAT), vol. 12, no. 13, pp. 885-903, 2021.

[18] A. P. Aaron, M. L. Kohlstrand, L. V. Welborn, and S. T. Curvey, "Maintaining medical record confidentiality and client privacy in the era of big data: ethical and legal responsibilities," Journal of the American Veterinary Medical Association, vol. 255, no. 3, pp. 282-288, 2019.

[19] B. J. Ali and M. S. Oudat, "Accounting information system and financial sustainability of commercial and islamic banks: a review of the literature," Journal of Management Information and Decision Sciences, vol. 24, no. 5, pp. 1-17, 2021.

[20] V. Brock and H. U. Khan, "Big data analytics: does organizational factor matters impact technology acceptance?" Journal of Big Data, vol. 4, no. 1, pp. 1-28, 2017.

[21] A. Sibi and S. Merin, "An investigation on accounting information system, Zambia," Shanlax International Journal of Management, vol. 8, no. 2, pp. 13-20, 2020. 